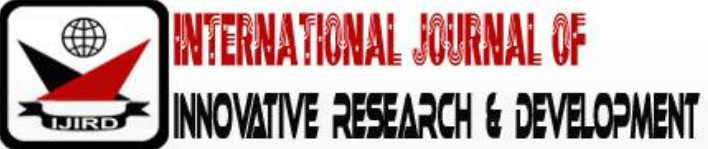

ISSN 2278-0211 (Online)

\section{Fetal Growth and Age Estimation based on Osteometry on the Diaphysis of Human Fetal Fibula}

\author{
Dr. Dhason Simon \\ Associate Professor of Anatomy, College of Health Sciences, Asella, Ethiopia \\ Dr. Biswajit Bhowmick \\ Senior Medical Officer, Army Medical Core, India \\ Dr. Monie Simon \\ Medical Officer, Chellaram Hospital, Pune, India \\ Dr. Don Varghese \\ Specialist Oral and Maxillofacial Surgeon, Saudi German Hospital, Dubai, UAE \\ Dr. Annie Varghese \\ Medical Director, IBN SINA Medical Centre, Dubai, UAE
}

\begin{abstract}
:
Very few osteometric studies are available on human fetuses dealing with fetal growth based on osteometric measurements. Earlier studies dealt with smaller sample size and measured only the length of long bones from chemically preserved fetuses. The present study is a pioneer one, measured on naturally maceratedfetal fibula bones. There have been six new osteometric measurements introduced on human fetal fibula. Maximum possible osteometric measurements taken on a record number of 912 fetal fibula bones from 456 fetuses having age range between 11 weeks to 40 weeks of intrauterine life. Bilateral and bisexual differences have been analyzed. Growth of fetal fibula has been analyzed, based on its osteometry. The fastest rate of growth is observed in fetal fibula in females during 11 to 16 weeks of the intrauterine life of human fetus. For every $1 \mathrm{~mm}$ increase in the CRL, the Maximum Length of Fibula (fi-ml) is increased by $.348 \mathrm{~mm}$ in the females. Regression values have been calculated to estimate human fetal age from the osteometric measurements on fetal fibula. Estimation of fetal age from the osteometry on fetal fibulais one of the crucial requirements in forensics.
\end{abstract}

Keywords: Fetus, fibula, osteometry, fetal growth, fetal age estimation

\section{Introduction}

Curiosity to know the mysterious phenomenon of intrauterine life of human does not limit itself in mere understanding of growth and development rather the significance of such knowledge lies on its clinical, anatomical and forensic applications. In the earlier attempts prenatal studies comparatively gave more attention on developmental factors, whereas the postnatal studies on growth aspects. Corlett (1986); Hazza (1990); Tsuzaki et al. (1990) dealt withgrowth on infants and children. Kulkarni (1985); Padmanathan et al. (1990) studied on children through adolescence and Macho(1986) dealt with adults. However less attention was given on the growth aspects on human in its intrauterine life based on osteometry. Although various studies have been carried out (Moss et al. 1955; Simon et al. 1984) on fetal growth aspects, the aims of those studies varied from one another. Most of the studies aimed to concentrate on developmental aspects rather than growth aspects (O'Rahilly 1973; Hamilton and Mossman 1976; Kulkarni et al. 1981). Few studiesaimed to estimate the age of related human fetus (Mehta and Singh 1972; Kosa 1997). Not only the aims but also methodology adopted by earlier workers varied considerably in preparing fetal specimens for carrying out fetal studies.Most of the earlier studies (Ford1956 and Moore and Persaud 1993) carried on human fetuses which were preserved in formalin. In someearlier studies, observations and measurements were taken from photographs (Burdi 1969), radiographs(Scheuer et al.1980) and ultrasonographs (Falkner and Roche 1987; Mankeekar 1993). Moss et al. (1955) studied fetal bones which were prepared with alizarin staining. In some other studies (Ford 1956; Mehta and Singh 1972) the fetal bones were dissected from preserved fetuses and measured. Mehta and Singh (1972) measured the crownrump length of fetuses, after fixing them in $10 \%$ formalin for 4 to 6 months. The sample size considered in the earlier studies also varied from one another. It has been noted that in many cases the number has been found to be quite inadequate. Feltz (1954) studied only 53 femora. Gray and Gardner (1969), Gardner and Gray (1970) studied a series of only 40 embryos and fetuses. Mehta and Singh (1972) measured the diaphyseal lengths of only 50 fetuses. Because of the inadequacy in sample size and variability in the sample size, no proper comparison could be made between the studies. In the case of osteometry, from the earlier studies, which were aimed to estimate the age from fetal long bones, it has been observed that not all the studies included all the long bones (Feltz 1954; Moss et al.1955; Gray and Gardner 1969; Gardner 
and Gray 1970; Mehta and Singh 1972).With different aims, variations in methodology adopted to prepare human specimens, with lesser number of parameters on too less sample size, the whole scenario depicts an unclear picture. Thus, it is felt necessary that a systematic study to be undertaken considering the pitfalls highlighted above. The present study would undertake a detailed osteometric study in dealing with growth aspects. Side differences, bisexual variations and age estimation would be analyzed. Such an anatomical effort on dealing with a large sample size with almost equal sex ratio, with maximum possible osteometric measurements on fetal fibula bones has never ever reported so far.

\subsection{Aims and Objectives}

The specific aims and objectives of the present study are:

- To assess bilateral differences, in the growth pattern on the basis of measurements taken on both sides' fibula bones of human fetuses.

- To find out the extent of bisexual differences, if any, in the growth pattern of human fetuses on the basis of metric analyses.

- To analyze the rate of fetal growth as exhibited through detailed osteometry.

- To correlate various osteometric measurements on fibula with crown-rump length (CRL) and crown-heel length (CHL) to estimate fetal age.

- To examine the applied significance of those selected measurements in terms of anatomical, clinical and medicolegal aspects.

\section{Material and Methods}

\subsection{Source of Fetuses}

Fetuses used for the purpose of the present study were collected from the Sassoon General Hospitals, Pune, India since 1978 onwards for over the period of 30 years. The fetuses were from abortions of Medical Termination of Pregnancies (MTPs)/Still Births. The collections of fetuses were done strictly by following official procedures. The study has been conducted in the Department of Anatomy, B.J. Medical College (BJMC), Pune, India and continued in the Department of Anatomy, Dr. V.M. Government Medical College, Solapur, India. Required approval was obtained from the Ethical Committee of BJMC.

\subsection{Population Base}

Anatomical significance of the present study is that the fetuses are from the population which belongs to a particular geographical area. In the present study, name of the parents of the fetuses and their place of living indicate that all these parents of the fetuses belong to the geographical area of the State of Maharashtra, India. This broad population base of Maharashtra provides a vital significance, indicating that the fetuses belong to the population based in Maharashtra State of India.

\subsection{Categorization of Fetuses}

There are 912 diaphyses of fetal fibula bones have been included for the present study from 456 human fetuses. Among the 456 fetuses, 244 (53.51\%)fetuses are males and 212 (46.49\%)fetuses are females. The fetuses which have been selected for the present study are of varying sizes ranging from $51 \mathrm{~mm}$ to $394 \mathrm{~mm}$ in crown-rump length (CRL) and 70 $\mathrm{mm}$ to $577 \mathrm{~mm}$ in crown-heel length (CHL). As there is earlier literature available to estimate fetal age from the CRL as well as the CHL, the present study has adopted the already established scales, (Davies 1967; Okajima 1975; Williams and Warwick 1980), to estimate fetal age based on the CRL and CHL. Osteometry has been carried out on all the 912 fibula bones. All the 456 fetuses have been categorized into four age groups, each group having eight weeks duration of age range, except for the first group. The first group has got only six weeks range, as because fetal bones are available for manual measurements only after the period of 11 weeks of the intrauterine development. (Table 1).

\begin{tabular}{|c|c|c|c|c|c|c|}
\hline \multirow{2}{*}{ Group } & \multirow{2}{*}{ Weeks } & \multirow{2}{*}{ CRL (mm) } & \multirow{2}{*}{ CHL (mm) } & \multicolumn{2}{|c|}{ Somatometry and Osteometry (456) } \\
\cline { 5 - 7 } & & & & Male & Female & Total \\
\hline I & $11-16$ & $51-100$ & Up to 150 & 18 & 4 & 22 \\
\hline II & $17-24$ & $101-200$ & $151-300$ & 159 & 152 & 311 \\
\hline III & $25-32$ & - & $301-400$ & 49 & 42 & 91 \\
\hline IV & $33-40$ & - & $401-550$ & 18 & 14 & 32 \\
\hline Total & & & & 244 & 212 & 456 \\
\hline
\end{tabular}

Table 1: Distribution of Human Fetuses for the Present Metric Study 


\subsection{Somatometry}

When a fresh human fetus was brought into the Department of Anatomy the fetus was cleaned by running water for about few minutes. The umbilical cord of the fetus was cut off and tied with a thread so that oozing of the blood from the fetus was made stopped. Sex of the fetus was noted down. There are two somatometric measurements selected for the present study (Table 2).

\begin{tabular}{|c|c|c|}
\hline S.No. & Somatometric Measurement & Abbreviation \\
\hline 1 & Crown-Rump Length & CRL \\
\hline 2 & Crown-Heel Length & CHL \\
\hline
\end{tabular}

Table 2: Somatometric Measurements

\subsection{Maceration}

Once the somatometry was completed the fetuses were kept in glass jars labeled with identification number and date of collection of the fetuses. The jars contained sufficient amount of water so that the fetuses could immerse inside the water. Then the glass jar containing the fetus was kept in a maceration room on the terrace of the department. The side walls of the maceration room weremade by metallic sieves so that sufficient air and sun light could beavailable. During the process of maceration live maggots start consuming the soft parts of the fetuses.The indication of the completion of the maceration was that no live maggots found in the jars and only few dead maggots found floating on the surface of the water. The harvested bones of the fetus were cleaned with water. The bones were filtered by metal sieve with minute holes to avoid losing even small bones. Although full sets of fetal bones of human fetuses were prepared, only fibula bones have been selected for the present study. As the epiphyses of the fibula bones are not formed during intrauterine life, only the diaphyses of fibula bones have been observed and measured (Fig.1).

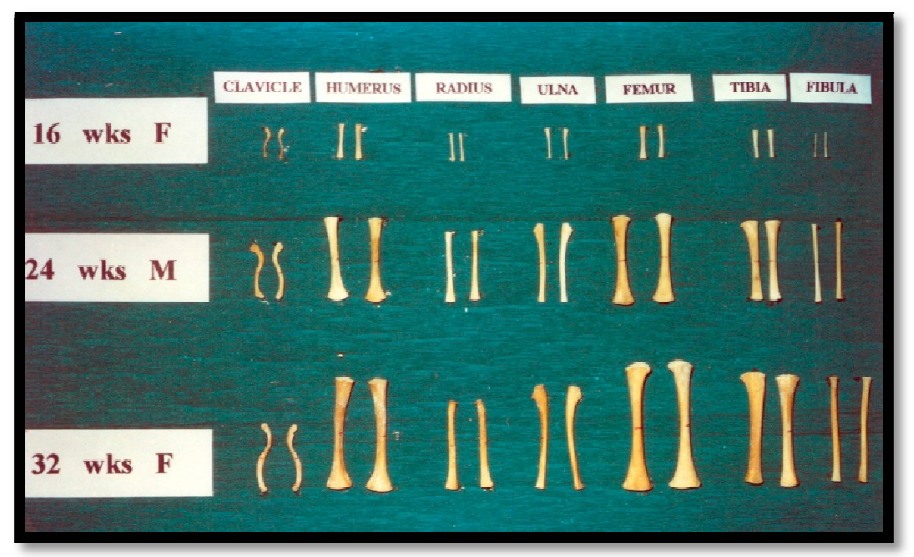

Figure 1: Shafts of Fetal Long Bones (16 to 32 weeks)

\subsection{Osteometry}

In addition to the two somatometric measurements, there have been seven osteometric measurements taken for the present study (Table 3). All the seven osteometric measurements have been measured on both right and left side bones. The following osteometric measurements taken on human fetal fibula are new measurements introduced in the present study except the maximum length of fibula.

\begin{tabular}{|c|c|c|}
\hline S.No. & Osteometric Measurement & Abbreviation \\
\hline 1 & Fibula-Maximum Length & fi-ml \\
\hline 2 & Fibula-Proximal Antero-Posterior Diameter & fi-pap \\
\hline 3 & Fibula-Proximal Medio-Lateral Diameter & fi-pml \\
\hline 4 & Fibula-Distal Antero-Posterior Diameter & fi-dap \\
\hline 5 & Fibula-Distal Medio-Lateral Diameter & fi-dml \\
\hline 6 & Fibula-Middle Antero-Posterior Diameter & fi-mml \\
\hline 7 & Fibula-Middle Medio-Lateral Diameter & \\
\hline
\end{tabular}

The maximum length of fibula is the maximum straight-line distance between the highest point on the proximal end and the lowest point on the distal end of fibula. The remaining measurements have been taken at the proximal/distal/middle part of fibula from the maximum straight-line distance from anterior/posterior/medial/lateral most points as per the name of the measurement.

\subsection{Number of Measurements}

The somatometric and the osteometric studies undertaken for the present work, are involved a very large number of measurements in order, taken on all the 456 fetuses. In all, there have been in order 7296 somatometric and osteometric measurements recorded on 456 fetuses 
(Table 4).

\begin{tabular}{|c|c|c|c|c|c|}
\hline \multicolumn{3}{|c|}{ Measurement } & \multicolumn{2}{|c|}{ Each Fetus } & \multirow{2}{*}{$\begin{array}{c}\text { Total on } \\
\text { Somatometry / } \\
\text { Osteometry on all } \\
\text { fetuses }\end{array}$} \\
\hline Name & Sample & Type & $\begin{array}{c}\text { Number } \\
\text { of Measurements }\end{array}$ & $\begin{array}{l}\text { Total Number } \\
\text { of } \\
\text { Measurements }\end{array}$ & \\
\hline Somatometry & 456 & Single & 2 & $(2 \times 1) 2$ & $(2 \times 456) 912$ \\
\hline Osteometry & 456 & Bilateral & 7 & $(7 \times 2) 14$ & $(14 \times 456) 6384$ \\
\hline \multicolumn{5}{|c|}{ Grand Total } & 7296 \\
\hline
\end{tabular}

Table 4: Details of Measurements on Human Fetuses

\subsection{Inter-age Groups}

As there are four age groups viz. I, II, III, IV, the absolute growth rate is calculated between these four groups. Thus, there are three inter-age groups formed I-II, II-III, and III-IV from the four basic groups. Each inter-age group has the total number of fetuses from both the groups concerned. The absolute growth rate has been calculated only for the Maximum Length of Fibula for the present study.

\subsection{Statistical Considerations}

Statistical considerations for calculating regression coefficients and tests of significance have been followed from Singh and Bhasin (1989). Calculation of absolute growth has been done by following the formula from Biswas and Bhattacharya (1966).

\section{Results and Discussion}

\subsection{Bilateral Differences}

Making availability of human fetuses in good number is itself a difficult task. Therefore, studies on human fetuses are comparatively rare. It is observed that even in the available earlier studies on fetal growth based on osteometry, side differences were not dealt with. Therefore, comparison of the bilateral differences of the present work with other studies is not attempted in the present study. In the present study in the males no significant bilateral difference has been observed. In the females, in the fi-pap, significant right-side dominance has been observed at $5 \%$ level from group II.It is observed that only $.89 \%$ shows significant bilateral differences in the osteometric measurements. Therefore, in the present study, all the analyses including the mean and standard deviations and correlation coefficients, regression analyses, analyses on growth and age estimation have been calculated on the basis of the mean values of both the left and right sides merging together.

\subsection{Bisexual Differences}

Significant differences have been found in between males and females in the fi-pml at 5\% level from group I; In the fi-ml and fi-mml at 5\% level and in thefi-pap, fi-pml, fi-dap, fi-dml, fi-dap at $1 \%$ level from group II; In the fi-ml at $1 \%$ level from group III. In all these measurements females show higher values. On the basis of the analyses, it has been observed that only $16.07 \%$ show significant bisexual differences. In spite of the low percentage of bisexual differences in the present study, all the obtained results on correlation coefficients, regression constants for growth rate and also scattergrams along with regression fit lines and bar diagrams have been presented sex wise separately for evolving a broad comparative perspective on both the sexes. Halonen (1929) while studying in a series of fetuses ranging from 100 to $500 \mathrm{~mm}$ (CHL) reported that the percentage of the length of the humerus occupied by the ossified part of the shaft and claimed to have found sexual differences in the extent of diaphyseal ossification, which was more advanced in female fetuses. Birkbeck et al. (1975) measured 149 fetuses ranging from 8 to 21 weeks for six measurements, which included CRL and CHL stated that the measurements were related to CHL and reported that there was no evidence of sex differences. The sex differences in the present study are analyzed based on four age groups but the same age group categories were not available in the earlier studies.

\subsection{Growth Rate}

While observing the earlier studies dealing with osteometry on human fetal long bones the earlier workers considered only the length of ossified shafts of long bones. But the present study not only deals with the length the ossified shafts of long bones but also introduced six new osteo-measurements on the diaphyses of the human fetal fibula for the first time. From the regression values (b0, b1) calculated for all the osteometric measurements (Tables 5 and 6), all the measurements show increasing trend of growth rate for every $1 \mathrm{~mm}$ increase in CRL and CHL. The b1 values show increase in the osteometric measurements for every one mm increase in CRL/CHL. Among all the measurements, the fi-ml shows faster rate of growth both in males and females. The fastest rate of growth is observed in fetal fibula in females from the group I ( 11 to 16 weeks). For every $1 \mathrm{~mm}$ increase in the CRL, the Maximum Length of Fibula (fi-ml) is increased by $.348 \mathrm{~mm}$ in females.In the group I (11 to 16 weeks) mostly females show higher values in all the osteometric 
measurements than males. The group II (17 to 24 weeks) shows slightly higher rate of growth when compare to group III (25 to 32 weeks) in most of the osteometric measurements in both males and females. The growth rates of all the measurements are higher in the group IV compare to the group Iinmales. Whereas in females the growth rates of all the measurements show lower values in the group IV compare to group I.

\begin{tabular}{|c|c|c|c|c|c|c|c|c|c|}
\hline \multirow{2}{*}{\multicolumn{2}{|c|}{$\frac{\text { FIBULA }}{\text { Males }}$}} & \multicolumn{2}{|c|}{ Group -I } & \multirow{2}{*}{\multicolumn{2}{|c|}{$\begin{array}{c}\text { Group -II } \\
17-24 w k s \\
(159)\end{array}$}} & \multirow{2}{*}{\multicolumn{2}{|c|}{$\begin{array}{c}\text { Group -III } \\
25-32 w k s \\
\text { (49) }\end{array}$}} & \multirow{2}{*}{\multicolumn{2}{|c|}{$\frac{\text { Group -IV }}{\text { 33-40wks (18) }}$}} \\
\hline & & \multicolumn{2}{|c|}{ 11-16wks (18) } & & & & & & \\
\hline $\begin{array}{c}\text { Dependent } \\
\text { Variable }\end{array}$ & $\begin{array}{c}\text { Independent } \\
\text { Variable }\end{array}$ & b0 & $\mathrm{b} 1$ & b0 & b1 & b0 & $\mathrm{b} 1$ & b0 & $\mathrm{b} 1$ \\
\hline fi-ml & CRL & -7.147 & .190 & -9.499 & .219 & 4.808 & .149 & -4.442 & .193 \\
\hline fi-pap & & -.038 & .010 & -1.086 & .020 & -.180 & .016 & -.429 & .017 \\
\hline fi-pml & & .057 & .009 & -.978 & .018 & -.437 & .016 & .234 & .014 \\
\hline fi-dap & & -.009 & .011 & -1.272 & .022 & -.834 & .021 & -1.394 & .023 \\
\hline fi-dml & & -.059 & .011 & -1.084 & .019 & -1.343 & .021 & -1.034 & .019 \\
\hline fi-map & & -.130 & .009 & -.338 & .011 & .052 & .009 & -2.137 & .016 \\
\hline fi-mml & & .016 & .006 & -.135 & .007 & -.205 & .007 & -.625 & .008 \\
\hline \multicolumn{2}{|c|}{ Females } & \multicolumn{2}{|c|}{ 11-16wks (04) } & \multicolumn{2}{|c|}{ 17-24wks (152) } & \multicolumn{2}{|c|}{ 25-32wks (42) } & \multicolumn{2}{|c|}{ 33-40wks (14) } \\
\hline fi-ml & CRL & -22.525 & .348 & -9.866 & .225 & -1.530 & .185 & -5.061 & .196 \\
\hline fi-pap & & -3.750 & .048 & -1.226 & .021 & .564 & .013 & -3.549 & .027 \\
\hline fi-pml & & -3.750 & .048 & -1.160 & .020 & .162 & .014 & -4.423 & .029 \\
\hline fi-dap & & -4.500 & .056 & -1.403 & .024 & .153 & .017 & -1.938 & .024 \\
\hline fi-dml & & -5.400 & .065 & -1.173 & .021 & .110 & .015 & -1.484 & .020 \\
\hline fi-map & & -5.700 & .065 & -.473 & .012 & .587 & .007 & -.993 & .013 \\
\hline fi-mml & & -3.750 & .044 & -.170 & .007 & -.048 & .007 & -1.114 & .010 \\
\hline
\end{tabular}

Table 5: Regression Values (B0, B1) for Growth Rate in Fibula with CRL in Four Age Groups in Males and Females B1 Shows Increase in the Osteometric Measurements for Every One Mm Increase in CRL Number in Parentheses Indicates Sample Size

\begin{tabular}{|c|c|c|c|c|c|c|c|c|c|}
\hline \multirow{2}{*}{\multicolumn{2}{|c|}{$\begin{array}{c}\text { FIBULA } \\
\text { Males }\end{array}$}} & \multirow{2}{*}{\multicolumn{2}{|c|}{$\frac{\text { Group -I }}{11-16 w k s ~(18)}$}} & \multirow{2}{*}{\multicolumn{2}{|c|}{$\begin{array}{c}\text { Group -II } \\
17-24 w k s \\
(159)\end{array}$}} & \multirow{2}{*}{\multicolumn{2}{|c|}{$\begin{array}{c}\text { Group -III } \\
25-32 w k s \\
(49)\end{array}$}} & \multirow{2}{*}{\multicolumn{2}{|c|}{$\begin{array}{c}\text { Group -IV } \\
33-40 w k s \\
\text { (18) }\end{array}$}} \\
\hline & & & & & & & & & \\
\hline $\begin{array}{c}\text { Dependent } \\
\text { Variable }\end{array}$ & $\begin{array}{c}\text { Independent } \\
\text { Variable }\end{array}$ & b0 & b1 & b0 & $\mathrm{b} 1$ & b0 & b1 & b0 & b1 \\
\hline fi-ml & CHL & -5.501 & .120 & -9.046 & .145 & $\begin{array}{c}- \\
2.402\end{array}$ & .121 & -7.221 & .138 \\
\hline fi-pap & & .060 & .006 & -1.032 & .013 & -.822 & .012 & -.476 & .012 \\
\hline fi-pml & & .146 & .005 & -.928 & .012 & $\begin{array}{c}- \\
1.017\end{array}$ & .012 & .102 & .010 \\
\hline fi-dap & & .097 & .007 & -1.203 & .015 & $\begin{array}{c}- \\
1.433 \\
\end{array}$ & .016 & -1.797 & .016 \\
\hline fi-dml & & .043 & .007 & -1.023 & .013 & $\begin{array}{c}- \\
2.071\end{array}$ & .016 & -1.240 & .013 \\
\hline fi-map & & -.052 & .005 & -.309 & .007 & -.291 & .007 & -2.250 & .011 \\
\hline fi-mml & & .080 & .004 & -.122 & .005 & $\begin{array}{l}.501 \\
\end{array}$ & .006 & -.732 & .006 \\
\hline \multicolumn{2}{|c|}{ Female } & \multicolumn{2}{|c|}{ 11-16wks (04) } & \multicolumn{2}{|c|}{$\begin{array}{c}\text { 17-24wks } \\
(152)\end{array}$} & \multicolumn{2}{|c|}{$\begin{array}{c}25-32 w \mathrm{ks} \\
(42)\end{array}$} & \multicolumn{2}{|c|}{$\begin{array}{c}\text { 33-40wks } \\
(14)\end{array}$} \\
\hline fi-ml & CHL & -19.220 & .214 & -9.252 & 147 & $\begin{array}{c}- \\
7.483\end{array}$ & .141 & -8.914 & .140 \\
\hline fi-pap & & -2.368 & .023 & -1.158 & .014 & -.095 & .010 & -1.862 & .014 \\
\hline fi-pml & & -2.368 & .023 & -1.074 & .013 & -.519 & .011 & -2.572 & .015 \\
\hline fi-dap & & -4.057 & .035 & -1.302 & .015 & -.569 & .013 & -1.378 & .015 \\
\hline fi-dml & & -3.911 & .034 & -1.091 & .013 & -.499 & .012 & -1.514 & .014 \\
\hline fi-map & & -5.534 & .043 & -.430 & .008 & .411 & .005 & -1.501 & .010 \\
\hline fi-mml & & -3.552 & .028 & -.145 & .005 & -.288 & .005 & -1.395 & .008 \\
\hline
\end{tabular}

Table 6: Regression values $(b 0, b 1)$ for growth rate in Fibula with $C H L$ in four age groups in males and females. b1 shows increase in the osteometric measurements for every one mm increase in CHL 
Studies on bone growth, based on quantitative analyses, help better understanding the growth pattern. On the basis of the analysis on osteometry, the present study reveals that there is a positive growth trend, which has been observed in all the measurements taken on the fetal fibula from all the four age groups considered. Saettle (1951) plotted growth curves of shafts against fetal height on the basis of the growth curve. Moss et al. (1955) also stated that the several combinations of osseous shaft lengths revealed a constant ratio between the specific growth rates of all the bones. Moss et al. (1955) measured 106 fetuses, which were cleared and stained with alizarin, ranging from $30 \mathrm{~mm}$ to $169 \mathrm{~mm}$ in CRL. Whereas in the present study, in the same age groups (I and II) there are 333 fetuses studied. The present osteometric study has been carried out on 912 dried bones from 456 fetuses. Variations observed with the earlier results (Table 7) might be attributed to the very less sample size of the earlier studies and the mode of preparation of the bone material for the osteometric study. Moss et al. (1955) noted a characteristic interphase in the growth of the body shaft in the CRL interval of $80-89 \mathrm{~mm}$. Before this interval, the body shafts of all the long bones grow relatively faster than the CRL and after that the growth rate was not as fast as it was before.

\begin{tabular}{|c|c|c|c|c|}
\hline Bone & \multicolumn{2}{|c|}{ Group I } & \multicolumn{2}{c|}{ Group II } \\
\hline \multirow{2}{*}{ Fibula } & Moss et al. (1955) & Present study & Moss et al. (1955) & $\begin{array}{c}\text { Present } \\
\text { Study }\end{array}$ \\
\cline { 2 - 5 } & 7.10 & 10.40 & 21.14 & 25.10 \\
\hline
\end{tabular}

Table 7: Mean of Maximum Length of Fibula: Comparison

Vare and Bansal (1977) observed a linear correlation between the diaphyseal lengths of upper and lower limbs and the CRL from 185 fetuses of 116 males and 69 females with CRL ranging from 185 - $415 \mathrm{~mm}$. The bones were dissected from the body and got them measured. Although the muscles and connective tissue were removed from the bones, periosteum was left intact. In the present study the periosteum got macerated during maceration process. In the earlier studies, the calculation of growth rate was not on the basis of age groups adopted by the present study. In the present study the growth rate has been calculated using regression equations, in all the four age groups under male and female categories separately, for all the osteometic measurements. Thus, in the present study a broad understanding has been evolved on the growth rate of fetal long bones, age wise and sex wise. Vare and Bansal (1977) reported that for every 1 $\mathrm{mm}$ increase in CRL the length of fibula increases by $0.18 \mathrm{~mm}$. Whereas the present study reports that the groups I, II, III and IV show $0.190 \mathrm{~mm}, 0.219 \mathrm{~mm}, 0.149 \mathrm{~mm}$ and $0.193 \mathrm{~mm}$ respectively in males and $0.348 \mathrm{~mm}, 0.225 \mathrm{~mm}, 0.185 \mathrm{~mm}$ and $0.196 \mathrm{~mm}$ respectively in females.

\subsection{Absolute Growth Rate}

Absolute growth rate for the Maximum Length of Fibulais higher in the inter-age group I-II (11 weeks to 24 weeks) and gradually declining through the proceeding two inter-age groups II-III (17 weeks to 32 weeks) and III-IV (25 weeks to 40 weeks). The fi-ml of males from the inter-age group I-II (11 weeks to 24 weeks) shows the highest absolute rate of fetal growth as $87.06 \%$ per month. The lowest absolute growth rate is found in the fi-ml of females from the interage group III-IV (25 weeks to 40 weeks) as $16.74 \%$ per month (Table 8).The bar diagram (Fig. 2) reveals the absolute growth rate for the Maximum Length of Fibulaof both males and females between the three inter-age groups. Thus, the prepared bar diagram not only helps to understand the trend of absolute growth rate but also shows with male-female differences.

\begin{tabular}{|c|c|c|c|}
\hline Sex & Intergroup I-II & Intergroup II-III & Intergroup III-IV \\
\hline Males & 87.06 & 29.05 & 21.89 \\
\hline Females & 58.96 & 28.56 & 16.74 \\
\hline
\end{tabular}

Table 8: Absolute Growth Rate Per Cent per Month the Maximum Length of Fibula for three Inter-age Groups of Human Fetuses

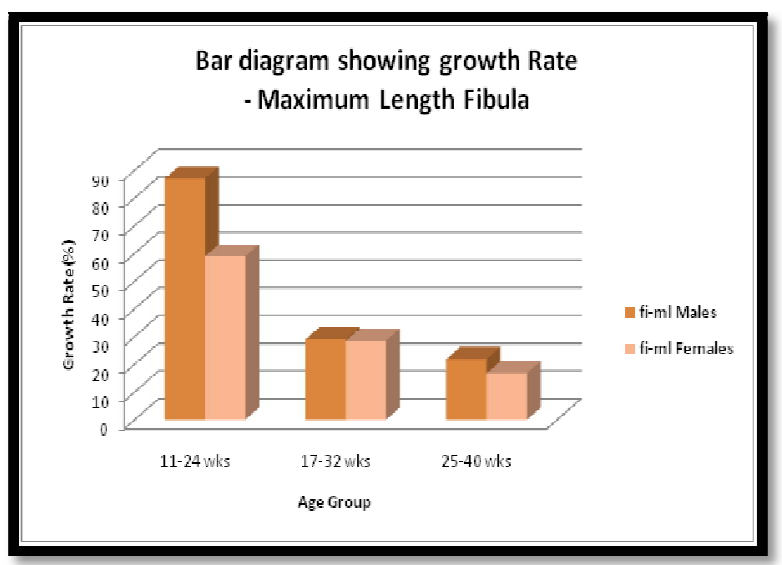

Figure 2: Absolute Growth Rate of Fetus Based on Maximum Length of Fibula 


\subsection{Bivariate Distribution}

In the case of osteometry, variations between CRL with the fi-ml have been computedfor males and females separately. Because of the smaller sample size in the groups I and IV, scatter diagrams have been prepared only for the groups II and III.The scattergrams show that there are very close relationships found between the CRL with fi-ml.The obtained scatter diagrams show a good fit between the variables correlated(Figs.3 and4).

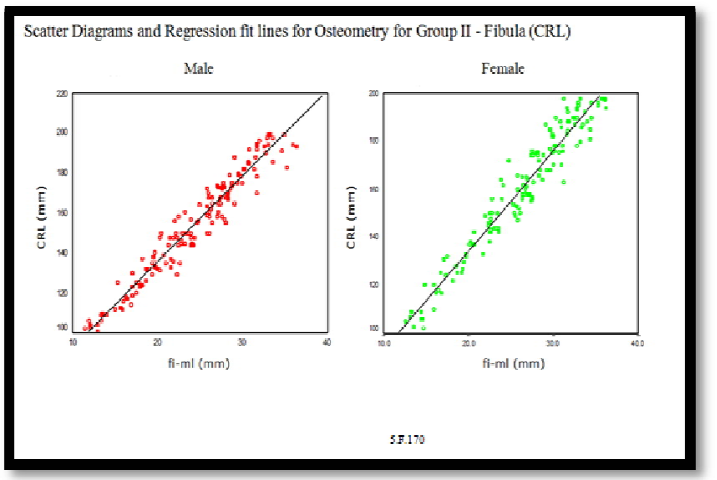

Figure 3: Scatter Diagrams and Regression Fit Lines for Osteometry for Group II-Fibula (CRL)

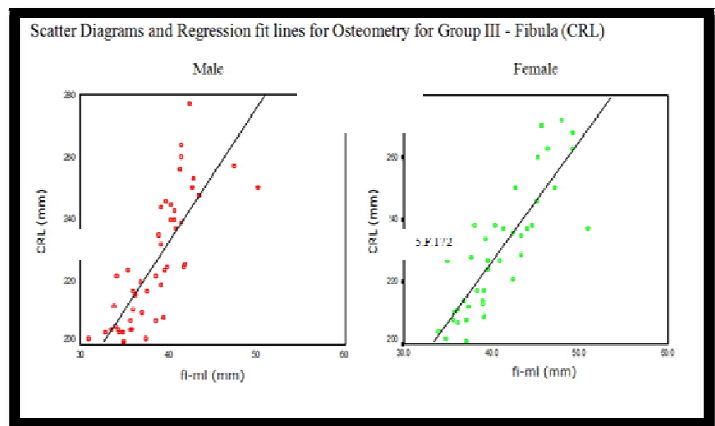

Figure 4: Scatter Diagrams and Regression Fit Lines for Osteometry for Group III-Fibula (CRL)

\subsection{Correlations}

There have been highly significant correlations obtained between the CRL/CHL with all the osteometric measurements in the present study. In the males, the highest value of correlation coefficient .991 at $1 \%$ level is found between the CRL and fi-ml in group I. In the females, the highest value .998 at 1\% level is found in between the CHL and fi$\mathrm{mml}$ in group I.

\subsection{Age Estimation of Human Fetus}

In the present study, the CRL and CHL are found closely correlated with all the osteometric measurements,which clearly reveal the dynamic relationships between the CRL/CHL with all the osteometric measurements.As there are already established scales available to estimate fetal age from CRL and CHL, it is restricted to calculate only the CRL and CHL from all the osteometric measurements for the purpose of the present study. Once the CRL/CHL is calculated, age can be estimated from the already established age estimation scale. Necessary regression values (b0, b1) have been calculated for osteometric measurements for age estimation. With the help of the tables 9 and 10, CRL and CHL can be calculated using the two values b0 and b1 and the given measurements.

The formula to calculate CRL/CHL is as follows:

$\mathrm{CRL} / \mathrm{CHL}=(\mathrm{b} 1 \mathrm{x}$ measurement $)+\mathrm{b} 0$

\begin{tabular}{|c|c|c|}
\hline Regression values (b0, b1) for estimating & \multicolumn{2}{|c|}{ Group -All } \\
\cline { 2 - 3 } CRL, from Fibula & b0 & b1 \\
\hline fi-ml & 39.110 & 4.733 \\
\hline fi-pap & 55.399 & 50.559 \\
\hline fi-pml & 56.649 & 52.883 \\
\hline fi-dap & 56.737 & 43.774 \\
\hline fi-dml & 56.405 & 50.250 \\
\hline fi-map & 42.929 & 85.584 \\
\hline fi-mml & 33.490 & 127.596 \\
\hline
\end{tabular}

Table 9: Regression Values (B0, B1) for Estimating CRL, from

Fibula from the Total Sample of 456 Fetuses 


\begin{tabular}{|c|c|c|}
\hline \multirow{2}{*}{$\begin{array}{c}\text { Regression values (b0, b1) for } \\
\text { estimating CHL, from Fibula }\end{array}$} & \multicolumn{2}{|c|}{ Group -All } \\
\cline { 2 - 3 } & b0 & b1 \\
\hline fi-ml & 57.883 & 7.067 \\
\hline fi-pap & 82.812 & 75.251 \\
\hline fi-pml & 84.808 & 78.652 \\
\hline fi-dap & 84.818 & 65.148 \\
\hline fi-dml & 84.276 & 74.805 \\
\hline fi-map & 63.910 & 127.599 \\
\hline fi-mml & 49.647 & 190.404 \\
\hline
\end{tabular}

Table 10: Regression Values (B0, B1) for Estimating CHL, from

Fibula from the Total Sample of 456 Fetuses

Legal authorities approach anatomy experts to know about theage and sex of the deceased from the available bone remains in dealing with suspected medico-legal cases. While examining the adult cases, as there are already established scales available for age estimation, it is easy to estimate the age of the deceased adult from the bone remains. On the contrary, when the opinion about the age of a deceased fetus is asked, from the available fetal bones, as there is no established scale or standards available, it is difficult to provide precise information regarding the age of fetus. Mehta and Singh (1972); Vare and Bansal (1977); Kosa (1997) attempted to estimate fetal age from fetal long bones from chemically preserved fetuses. Simon et al. (1992); Simon and Baig (2015) ${ }^{\text {a }}$; Simon and Baig (2015) estimated CRL/CHL from fetal clavicle, fetal humerus and fetal femur respectively. The latter studies were carried out on naturally macerated fetal bones without adding any preservatives. In the present study, once the CRL/CHL is calculated from the analyzed regression values, based on the osteometric study on fetal fibula bones, age can be estimated from the already established age estimation scale. By using the formula created in the present study, which would help to estimate the fetal age from the osteometric measurements taken on human fetal fibula.

\section{Summary and Conclusion}

The present study is a departure from the earlier attempts. The largest ever sample size of 912 fetal fibula bones from 456 human fetuses considered by any other study on human fetal fibula. Among them 244 (53.51\%) fetuses are males and $212(46.49 \%)$ are females. The fetuses are of different sizes belong to 11 weeks to 40 weeks of intrauterine life. In addition to CRL and CHL there are seven osteometric measurements attempted on diaphysis of human fetal fibula. Except the Maximum Length of Fibula all the remaining six osteometric measurements are newly introduced for the present study. Total in order there are7296 measurements taken. Somatometric measurements have been taken directly on freshly collected fetuses. All the earlier studies had been undertaken on chemically preserved fetuses / photographs /radiographs / uitrasonographs. Though time consuming, natural process of maceration has been adopted for the first time to prepare fetal bonesfor the osteometric study. No chemicalwas used for the preparation of bones. The harvested and cleaned bones were dried in normal room temperature before taking measurements. It is observed that only $0.89 \%$ shows significant bilateral differences in the osteometric measurements. It has been observed that only $16.07 \%$ show significant bisexual differences. Among all the measurements, the fi-ml shows faster rate of growth both in males and females. The fastest rate of growth is observed in the female fibula from the group I (11 to 16 weeks). For every $1 \mathrm{~mm}$ in the CRL, the Maximum Length of Fibula(fi-ml) is increased by $0.348 \mathrm{~mm}$. The CRL and CHL are found closely correlated with all the osteometric measurements. Variables of regression equations are calculated for fetal age estimation. The applied significance in the clinical aspects in the present study will enable us to advance a standard which would help to comprehend the differential growth pattern between normal and abnormal fetuses. While dealing with medico-legal cases involving fetus, the estimation of age of human fetus is a crucial factor. The population based prospective of this study on human fetal growth pattern would provide scope for comparison with other similar studies.

\section{References}

i. Birkbeck J A, Billewicz W Z, Thomson A M 1975 Foetal growth from 50 to 150 days of gestation. Annals of Human Biology 2(4): 319-326.

ii. Biswas P C, Bhattacharya D K 1966 Growth trends in Northern Indian population variation of four anthropometric traits from birth to maturity. In: Malhotra M S (ed) Human adaptability to environments and physical fitness. Defence Institute of Physiology and Allied Sciences, Madras.

iii. Burdi A R 1969 Cephalometric growth analysis of the human upper face region during the last two trimesters of gestation. Am J Anat 125: 113-122.

iv. Corlett JT (1986) Growth of urban school children in Botswana. Annals of Human Biology, 13 (Pt 1): $73-82$

v. Davies D V 1967 (ed) Gray's Anatomy. 34th edn. p 261. Longmans, Green, London.

vi. Falkner F, Roche A F 1987 Relationship of Femoral Length to Recumbent Length and Stature in fetal, neonatal and early childhood growth. Human Biology 59(5): 769-773.

vii. Feltz W J L 1954 the prenatal development of the human femur. Am J Anat 94: 1-44.

viii. Ford E H R 1956 the growth of the fetal skull. J Anat 90: 63-72.

ix. Gardner E, Gray D J 1970 the prenatal development of the human femur. Am J Anat 129: 121-140.

X. Gray D J, Gardner E 1969 the prenatal development of human humerus. Am J Anat 124: 431-446. 
xi. Halonen L 1929 Roentgenologisch-anatomische Untersuchungen uber die Entwichlung der Knochen der freien Extremiteten beim Menschen. I. Die Extremitetenknochen der Feten.

Societatis Medicorum Fennicae 'Duodecim'. Suonalaisen Laakariseuram 'in Toimituksia, Tom XI, Fasc. 3: 1-151 Helsinki.

xii. Hamilton W J, Mossman H W 1976 Human Embryology $4^{\text {th }}$ edn. Macmillan Press, London.

xiii. Hazza M AL-Hazza 1990 Anthropometric measurements of Saudi boys aged 6-14 years. Annals of Human Biology 17(1): 33-40.XIV. Kosa 1997 Determination of body length and age of human foetuses and newborns on the basis of weights of limb bones. Acta Biol Szeged 42: 225-234.

xiv. Kulkarni D S, Simon D, Bhanu B V 1981 Dermatoglyphic study on human foetus.J Anat Sci 3(1):47-52.

xv. Kulkarni V S 1985 Profiles of growth of two Endogamous groups. Unpublished Ph. D. Thesis. Dept. of Anthropology, University of Pune.

xvi. Macho G A 1986 Cephalometric and craniometric age changes in adult humans. Annals of Human Biology 13(1): 49-61.

xvii. Mankeekar P 1993 Fetal Growth. An Anthropological analysis of sonography. Unpublished M.Sc. Thesis. Dept of Anthropology, University of Pune.

xviii. Mehta L, Sing H M 1972 Determination of Crown-Rump length from Foetal long bones Humerus and Femur. Am J Phys Anthrop 36: 165-168.

xix. Moore K L, Persaud T V N 1993 (eds) The Developing Human - Clinically Oriented Embryology. 5 th edn. Saunders, Philadelphia.

xx. Moss M L, Noback C R, Robertson G G 1955 Critical development horizons in human fetal long bones. Am J Anat 97: $155-175$.

xxi. Okajima M 1975 Development of dermal ridges in the fetus. J Med Genet 12: 243-250.

xxii. O'rahilly R 1973 Developmental stages in human embryos. Part A. Embryos of the first three weeks (stages 1-9). pp 9-31. Carnegie Institution of Washington, Washington.

xxiii. Padmanathan G, Prakash S, Chhibber S R 1990 Single occasion means of height and weight of Sri Lankan Tamil children from Jaffna. Annals of Human Biology 17(2): 107-113.

xxiv. Saettle R 1951 Korpergroszenbestimmung Menschlicher Fruchte and Hemd der Langemasze einzelner Skeletteile oder der on Diphysen. Dtsch.Z. Ges gerichtl Med 40: 567-577. Scheuer J L, Musgrave J H, Evans S P 1980 The estimation of late fetal and perinatal age from limb bone length by linear and logarithmic regression.Annals of Human Biology 7(3): 257-265.

xxv. Simon D, Kulkarni D S, Gore A P, Bhanu B V, Patwardhan S 1984 Somatometric study on human foetus. J Anat Sci 6: $1-6$

xxvi. Simon D, Deshmukh A N, Bhanu B V 1992 Age estimation from human foetal clavicle.Med J West India 20: 58-62.

xxvii. XXIX. Simon D, Baig M M 2015 a Growth analysis and age estimation of human fetus from human fetal humerus. IJIRD Vol 4 Issue 5: 142-147.

xxviii. Simon D, Baig M M 2015 browth pattern and fetal age estimation from the diaphyseal length of femur. IJIRD Vol 4 Issue 5: 148-152.

xxix. Singh I P, Bhasin M K 1989 Anthropometry. Bharti Bhavan, Kamla-raj Enterprises, N. Delhi.XXXII. Tsuzaki S, Matsuo N, Saito M, Osano M 1990 The head circumference growth curve for Japanese children between 0-4 years of age: Comparison with Caucasian children and correlation with stature. Annals of Human Biology 17(4): $297-303$.

xxx. Vare A M, Bansal P C 1977 Estimation of Crown-Rump length from diaphyseal lengths of fetal long bones. J Anat Soc India 26(2): 91-93.

xxxi. Williams P L, Warwick R 1980 (eds) Gray's Anatomy. 36 ${ }^{\text {th }}$ edn. Churchill Livingstone, Edinburgh. 